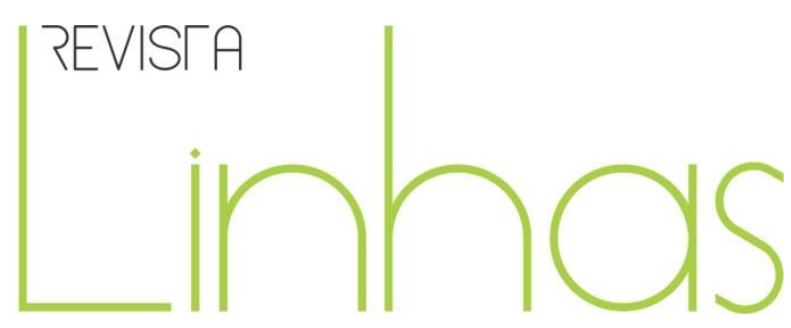

\title{
Classe de Aceleração e seus desdobramentos: um estudo em uma escola da rede pública municipal
}

\section{Resumo}

O presente artigo é resultado de uma pesquisa, finalizada em 2017, sobre Classes de aceleração. Tem como eixo central a implantação da Aceleração da Aprendizagem, como política educacional em âmbito nacional e seus desdobramentos em uma escola pública da rede municipal do ensino fundamental, no Oeste de Santa Catarina. A pesquisa realizada contou com observações, análise de documentos e entrevistas com professores e alunos da Classe de Aceleração, ano de 2016. O artigo trata das principais ações educativas e mudanças que foram sendo realizadas desde a implantação desta classe na escola pesquisada e, particularmente, a realidade dos alunos, considerando como vivenciaram a experiência na classe e na escola. Finalizamos com uma reflexão sobre a política de Aceleração da Aprendizagem que separa os alunos em situação de discrepância idade-série, reforçando diferentes formas de preconceito e discriminação que, dissimuladamente, vão se perpetuando nos ambientes escolares. Entre os autores pesquisados, citamos Mainardes (2007); Poli (2003) e Bourdieu (1992, 2012).

Palavras-chave: Classe de Aceleração. Ensino Fundamental. Desigualdades Educacionais.

\author{
Claudiomiro da Silva \\ Secretaria de Educação de São \\ Lourenço do Oeste/SC - Brasil \\ claudiomiroo7@hotmail.com \\ Nadir Zago \\ Universidade Comunitária da \\ Região de Chapecó - \\ Unochapecó - Chapecó/SC - \\ Brasil \\ nadirzago@uol.com.br
}

\section{Para citar este artigo:}

SILVA, Claudiomiro da; ZAGO, Nadir. Classe de Aceleração e seus desdobramentos: um estudo em uma escola da rede pública municipal. Revista Linhas. Florianópolis, v. 20, n. 42, p. 217-237, jan./abr. 2019. 


\title{
Acceleration Class and its deployment: a study in a school of the municipal public network
}

\begin{abstract}
This article is the result of a search, completed in 2017, about Acceleration Classes. Its central axis is the implementation of Acceleration of Learning, as an educational policy at the national level and its developments in a public school of the municipal network of elementary education, in the West of Santa Catarina. The research carried out included observations, document analysis and interviews with teachers and students of the Acceleration Class, year 2016. The article deals with the main educational actions and changes that have been carried out since the implantation of this class in the school researched and, in particular, the reality of the students, considering how they experienced the experience in class and in school. We conclude with a reflection about policy of acceleration of learning that separates students in a situation of age-series discrepancy, reinforcing different forms of prejudice and discrimination that are hidden in school environments. Among the authors researched, we mention Mainardes (2007); Poly (2003) and Bourdieu (1992, 2012).
\end{abstract}

Keywords: Acceleration Class. Elementary School. Educational Inequality. 


\section{Introdução}

A proposição deste artigo busca responder em que medida o processo de instituição das Classes de aceleração, em âmbito nacional e seus desdobramentos em uma escola pública do ensino fundamental da rede municipal, no Oeste de Santa Catarina, apresentou mudanças e/ou reforçou permanências das velhas práticas pedagógicas com alunos que estão com atraso escolar. Para dar conta deste objetivo geral, desenvolveremos uma análise tendo por base as seguintes questões: 1) Em que medida a Classe de Aceleração, inserida em uma escola da rede pública do ensino fundamental, apresentou estratégias concretas para a inclusão escolar? 2) Quais mudanças foram possíveis na escola para superação da discriminação de alunos marcados pelo atraso escolar? 3) Considerando que a Classe de Aceleração foi instituída para reduzir a discrepância idade e série, o que dizem os alunos desta classe e como vivenciaram essa experiência?

Para responder essas questões, nos apropriamos de parte dos resultados que subsidiaram nossa dissertação de mestrado, defendida em 2017. O estudo empírico foi realizado em uma escola do ensino fundamental da rede pública municipal de São Lourenço do Oeste - Santa Catarina. A metodologia adotada é predominantemente qualitativa, mantendo a necessária articulação com dados quantitativos associados às questões investigadas. A presença de um de nós no campo de pesquisa, na condição de ex-professor da escola, assim como o conhecimento da realidade social do contexto estudado, favoreceu a receptividade e aceitação para realização da pesquisa.

Durante a permanência na escola, foram realizadas observações e entrevistas, semiestruturadas, com professores, com a direção da escola e com alunos da Classe de Aceleração, assim como a análise de documentos, como as atas dos conselhos de classe, entre outros pertinentes às questões estudadas. Esse conjunto de procedimentos, realizado com visitas semanais à escola por um período de seis meses, facilitou a dinâmica da pesquisa, na obtenção e análise dos dados. Considerando o período de permanência no local e os procedimentos metodológicos adotados, nosso objetivo foi realizar uma etnografia da Classe de Aceleração na escola pesquisada. 
A Classe de Aceleração ou Correção de Fluxo, como foi chamada quando implantada em 2012 na rede municipal de educação, recebeu, na escola local de pesquisa, a denominação de Classe A. Essa mudança na designação foi uma forma encontrada na instituição para minimizar os preconceitos que acompanharam a classe desde a sua implantação. Entendemos, portanto, que limitar o estudo apenas às políticas educativas concernentes à Classe de Aceleração e suas normativas presentes na legislação, reduziria ou mesmo deixaria à margem o conhecimento de "outros momentos dos processos de política e atuação das políticas que acontecem dentro e em torno das escolas" (BALL; MAGUIRE; BRAUN, 2016, p. 13). É na perspectiva de conhecer processos que se produzem cotidianamente na escola e que revelam a realidade não documentada do ambiente escolar (EZPELETA; ROCKWELL, 1986), que reside nosso interesse de estudo. Preocupamo-nos em conhecer quais foram os objetivos e ações concretos desenvolvidos na escola e se eles ressignificaram e geraram mudanças na caminhada da classe em questão. Além disso, objetivamos conhecer igualmente como os alunos vivenciaram esse processo.

\section{Do sistema de ciclos às Classes de Aceleração}

Para contextualizar as questões de pesquisa acima citadas, situamos um breve histórico sobre a implantação das Classes de Aceleração, enquanto política nacional, inicialmente chamada de Ciclos. Esta proposta para atender os alunos com distorção idade e série no Brasil foi amparada por uma política educacional que nasceu da necessidade de encontrar respostas para atender uma demanda das escolas brasileiras. Segundo Mainardes (2007, p. 50), a palavra "Ciclo" foi utilizada pela primeira vez por Wallon para se referir ao período de desenvolvimento humano. Fazendo parte das chamadas “pedagogias invisíveis”, o ciclo é uma proposta oferecida aos alunos para proporcionar uma outra metodologia de aprendizagem. A sua implantação, muitas vezes, se deu pela eliminação total ou parcial da reprovação, e a inclusão de mais um ano no Ensino Fundamental. Na educação brasileira, acrescenta Mainardes, o termo “ciclo" já aparecia na Reforma de Francisco Campos, na década de 1930 e na lei Orgânica do Ensino 1942/46, e era utilizado para designar o agrupamento dos anos de estudo. De acordo com Poli (2003, p. 21), a implantação do sistema por ciclos de formação, não se deu 
harmonicamente. Houve divergências nesse processo entre os profissionais da educação que de um lado, eram de um grupo mais político-partidário; e desejavam o insucesso da proposta e; de outro lado, havia um grupo motivado pelo desafio de construir nas escolas uma proposta emancipadora para a educação.

De acordo com Mainardes (2007), as experiências que sucederam à implantação dos ciclos foram registradas nos grupos escolares dos estados do Paraná, em 1903, e de Minas Gerais, em 1906. No Paraná e Minas Gerais, os grupos escolares começaram a ser construídos nas capitais e, num segundo estágio, nas cidades de interior. Esse regime de trabalho em ciclos, como uma espécie de promoção automática, produziu novos problemas, aumentando as taxas de reprovação e evasão. Com o passar do tempo, "essas questões tornaram-se graves ao sistema educacional brasileiro que, historicamente, tem acumulado altos índices de reprovação e evasão" (MAINARDES, 2007, p. 57). O autor afirma ainda, que "ao ser implantado de forma impositiva e centralizadora, o Projeto Ciclos de Aprendizagem não criou condições para o desenvolvimento de uma educação mais democrática do que o sistema seriado, na qual os professores seriam envolvidos no processo de decisão e construção curricular" (MAINARDES, 2007, p. 124).

Ainda, segundo Mainardes (2007, p. 57), os Ciclos de aprendizagem "nascem da lógica de que os ciclos de formação por idade parecem representar a 'cura' do fracasso escolar, ou como uma estratégia para evitar a progressão automática ou em massa". Foram iniciativas, que na maioria das vezes aconteceram sem uma avaliação das garantias efetivas de aprendizado e, do modo como foram aplicadas, denotaram a própria insegurança e a vulnerabilidade dos processos.

Considerando esse breve processo histórico no sentido de correção das distorções de idade e série, iniciado com os ciclos, outra política educacional adotada para o enfrentamento da reprovação escolar foi a Aceleração da Aprendizagem, cujas justificativas foram: reduzir as taxas de reprovação e evasão; regularizar o fluxo escolar (racionalização); eliminar a "cultura da repetência"; melhorar a "eficácia" do sistema educacional (MAINARDES, 2007, p. 55). Inicialmente conhecido como Classe de Aceleração, esse programa foi instituído em 1997 pelo Ministério da Educação e Cultura (MEC). De acordo com Coimbra (2008, p. 55), o mesmo programa designa uma estratégia que parte 
do princípio de que o nível de maturidade dos alunos permite uma abordagem mais rápida dos conteúdos, o que lhes faculta a possibilidade de recuperar a defasagem entre a idade e a série que deveriam cursar.

Esse programa chega, em 1998, na rede estadual de ensino do Estado de Santa Catarina, com o nome de Classes de Aceleração, sob a coordenação dos técnicos em assuntos educacionais, do Núcleo de Apoio Pedagógico da Secretaria de Estado da Educação e do Desporto (SANTA CATARINA. Secretaria de Estado da Educação e do Desporto, 1999), abrangendo o atendimento de crianças com necessidades especiais. Em 1998, a Secretaria Estadual de Educação definiu, através do documento Apostila Classes de Aceleração, formas e níveis de responsabilidades de implantação das classes nas diversas instâncias (SANTA CATARINA. Secretaria de Estado da Educação e do Desporto, 1999, p. 10). A implantação em Santa Catarina guarda muitas semelhanças, nos seus textos, com o Programa nacional de Aceleração da Aprendizagem, assim como da Portaria 005/98, que regulamentou a implantação do projeto de $1^{\mathrm{a}}$ a $4^{\mathrm{a}}$ séries do Ensino Fundamental ${ }^{1}$. Paim (2015, p. 244), analisando esse processo de implantação das Classes de Aceleração a partir da Proposta Curricular de Santa Catarina, argumenta que o sistema escolar também gera sofrimentos nos alunos, nem sempre percebidos na escola, e que não sendo reconhecidos "passam a ser admitidos e legitimados (...) como se a responsabilidade do fracasso escolar fosse uma condição estritamente pessoal". Posteriormente, ilustraremos esse mal-estar discente com os dados de nossa pesquisa.

Como já havia sido implantada a Classe de Aceleração na Rede Estadual de Educação, a Secretaria Municipal de Educação de São Lourenço do Oeste - SC, município local da pesquisa, em 2012, incorpora a proposta com o objetivo de melhorar e/ou favorecer a aprendizagem dos alunos com distorção de idade e série nos anos finais do Ensino Fundamental. Amparada pela LDB (Lei de Diretrizes de Base, 1996) a reformulação

\footnotetext{
${ }^{1}$ A lei complementar $n^{\circ} 170 / 98$ inicia a política de aceleração da aprendizagem em Santa Catarina sobre o sistema estadual. Com a portaria 005/98, regulamentou a implantação do projeto de $1^{\mathrm{a}}$ a $4^{\mathrm{a}}$ séries do ensino fundamental. A Portaria 188/99 permitiu a criação de classes de aceleração para o nível III, ampliando o atendimento de alunos das séries finais do ensino fundamental e a portaria $\mathrm{n}^{\circ}$ 010/01 possibilitou a criação do nível IV, para alunos com defasagem no ensino médio. Em Santa Catarina, a rede pública estadual de ensino, que implantara as primeiras classes de aceleração em 1998, encerrou o projeto em 2003, quando da posse do governador Luiz Henrique da Silveira (COIMBRA, 2008, p. 99-100).
} 
da Lei Municipal ${ }^{2}$ em Educação e o Decreto de criação da Classe de Aceleração, garantiram a legitimidade da proposta. Também, foram definidos critérios, pela Secretaria de Educação, para a contratação de professores, assim como para a escolha e seleção das escolas, através da observação dos índices de reprovações (IDEB), e ainda da seleção dos alunos para compor as turmas de aceleração. Esses e outros aspectos foram pontos estratégicos pensados e estruturados para o início das atividades com a Classe de Aceleração no município.

Implantada no município em 2012, através do Decreto n 1.779, de 19 de dezembro de 2008 (SÃO LOURENÇO DO OESTE (SC), 2008), inicialmente designada Correção de Fluxo, a proposta para o Programa de Aceleração de Aprendizagem tinha por objetivo atender os alunos da educação básica, do $6^{\circ}$ ao $9^{\circ}$ ano do Ensino Fundamental. A meta principal era corrigir em cem por cento a distorção de idade e série, promovendo a inserção também de alunos com deficiência, sob análise da Fundação Catarinense de Educação Especial. Para isso, a Secretaria Municipal de Educação elegeu um corpo técnico de profissionais para estruturar e assessorar o trabalho com as turmas incluídas no programa. Com a exigência de readequação didático-pedagógica, de local e de metodologia de trabalho, foi necessária também muita determinação das pessoas envolvidas com o programa, pois faltava estrutura física nas escolas selecionadas, assim como materiais didáticos. Desde a sua homologação, o citado Decreto Municipal previa duração temporária para o programa, por um período de no máximo cinco anos ou até que houvesse necessidade de correção das distorções de idade e série nas duas escolas atendidas.

A proposta de criação da Classe de Aceleração nasce muito mais da necessidade de ampliar o horizonte de compreensão do ensino-aprendizado, com a defesa de uma práxis transformadora, portanto, não se limitando apenas a formar classes específicas para aqueles alunos com distorções de idade e série. Conforme afirma Poli (2003), separar os alunos em classes diferentes não garante alternativas pedagógicas eficazes sem uma ação concreta para acolher esses diferentes. Torna-se necessário considerar que “esse aluno é sujeito histórico ativo, possuindo saberes e vivências que constituem o

\footnotetext{
${ }^{2}$ Dispõe sobre a Reformulação do Sistema Municipal de Ensino e dá outras providências, conforme Art. $6^{\circ}$, do Decreto ${ }^{\circ}$ 1.779, de 19 de dezembro de 2008.
} 
ponto de partida e de chegada de uma práxis pedagógica transformadora" (POLI, 2003, p. 90).

Nessa relação com o diferente, seja por estar em situação de atraso escolar ou em outras formas de desigualdade, é preciso romper com a ideia de que nas escolas somos todos iguais e de que todos são tratados com os mesmos direitos e com os mesmos critérios. Isso pode até parecer justo, mas não acontece, e tampouco garante legitimidade se, de fato, não conhecermos e não levarmos em consideração, nas práticas efetivas da escola, o histórico pessoal e escolar dos estudantes. Conforme observa Candau (2011, p. 247), a escola tem papel importante para "empoderar sujeitos socioculturalmente subalternizados e negados". Acrescenta que, para desempenhar essa função de uma educação democrática e justa, a escola precisa estar didaticamente instrumentalizada, o que implica em processos de "diálogo entre diferentes conhecimentos e saberes", assim como "a utilização da pluralidade de linguagens, estratégias pedagógicas e recursos didáticos, a promoção de dispositivos de diferenciação pedagógica e o combate a toda forma de preconceito e discriminação no contexto escolar" (CANDAU, 2011, p. 253).

É olhando para esse panorama da implantação das Classes de aceleração no Brasil e no estado, assim como da defesa de uma escola democrática e justa, como sinaliza Candau, que apresentaremos como se deu parte desse processo em nosso campo de pesquisa, em uma escola da rede pública de ensino.

\section{A Classe de Aceleração na escola pesquisada}

Os resultados da pesquisa permitem situar o cenário do que foi a classe na escola pesquisada e as estratégias de mudanças que foram sendo construídas. Revelam igualmente a complexidade e o empenho dos agentes envolvidos nesse processo, sejam eles professores, gestores e, de modo especial, os alunos. A classe, vista a partir do chão da escola e da configuração sociocultural dos alunos pesquisados, nos ajuda a compreender que o processo de mudanças e de permanências de velhas práticas escolares faz parte do conjunto da obra. Práticas essas que muitas vezes apenas mudam de forma, permanecendo os preconceitos com características dissimuladas. 
De acordo com a descrição da professora titular ${ }^{3}$, no início das atividades com a classe, esses alunos eram "[...] em sua quase totalidade, reprovados e moradores do Morro do Piolho ${ }^{4}$, representando para a escola um dos seus maiores desafios". Alunos com problemas familiares, econômicos entre outras mazelas sociais, eles estavam expostos ou "escondidos em uma salinha", muitas vezes relegados a toda sorte de rotulações. Acrescenta ainda a mesma professora: "Era uma situação bem difícil. Mil vezes deu vontade de desistir".

Localizada muito próxima do centro da cidade e de um bairro popular, a escola passou a receber um contingente de alunos social e culturalmente heterogêneo. Em 2012, primeiro ano de funcionamento da escola e da Classe de Aceleração, foram 737 matrículas iniciais e 728 finais, com um índice de reprovação de 11,54\%. A média de reprovação somente para os alunos de $6^{\circ}$ ao $9^{\circ}$ ano era de $8,21 \%$. O IDEB, em 2013, apresentava uma nota expressiva de 6.3, muito embora em 2015 essa nota tenha sido rebaixada para 6.1.

A Classe de Aceleração, nos seus dois primeiros anos de funcionamento (2012-13), era formada por 18 meninos, número consideravelmente superior ao de meninas, que eram apenas 4. Situação muito parecida pode ser observada em 2015, enquanto que, em 2014, nota-se uma diminuição da diferença na composição da classe segundo o sexo, com 7 meninas e 11 meninos. Em maior ou menor grau, o número majoritário de meninos na classe ainda persiste e, em 2016, houve um total de 15 meninos para 9 meninas. A maior presença masculina em todos os anos letivos na Classe de Aceleração corrobora análises que indicam maior proporção de reprovações e discrepância de idade e série entre os meninos.

É diante desse quadro que Carvalho (2004, p. 248) observa que os registros escolares que evidenciam maior presença masculina entre os alunos com atraso escolar, não são simples constatações numéricas. Essas evidências encontram explicações apoiadas em estudos que vão demonstrar essa relação hierarquizada, principalmente de

\footnotetext{
${ }^{3}$ Denominamos professora titular, pois trabalhava em tempo integral com a turma da Classe de Aceleração.

4 Bairro popular, localizado na parte alta da cidade que corresponde ao atual Bairro Cruzeiro. Este, inicialmente denominado Morro do Piolho, com uma população de reduzidos recursos socioeconômicos, sofreu transformações com as primeiras indústrias instaladas na cidade, compondo um aglomerado de pessoas e de casas na parte alta da cidade, que se espremem entre vielas estreitas ou "carreiros", onde em algumas delas não é possível circular nem sequer de moto.
} 
jovens oriundos das camadas mais pobres, que podem reagir como forma de poder, para demonstrar sua masculinidade. A autora firma ainda que

[...] é a instrumentalização do fracasso acadêmico através da classificação e hierarquização competitivas, o que também trouxe à tona a questão de que são meninos a maioria dos 'fracassados'. Da mesma forma, grupos culturais e étnicos de jovens também teriam um papel significativo nesse processo, ao valorizar formas de afirmação baseadas, entre outros valores, na capacidade de transgredir e enfrentar as regras escolares. (CARVALHO, 2004, p. 279)

Em relação à composição socioeconômica, conforme dados de 2016, das 18 famílias dos alunos pesquisados, em 15 delas a renda mensal era de até três salários mínimos. Nesse grupo, a renda de uma delas era de um salário mínimo, duas declararam viver do auxílio Bolsa Família e as demais com recursos entre dois e três salários. Três não informaram. Portanto, os alunos que frequentaram a Classe de Aceleração no ano da pesquisa, eram originários de famílias de baixa renda. Em relação à questão étnica, predominavam filhos de descendentes de italianos. Esse dado é interessante do ponto de vista da história regional, e mesmo local, pois nessa região a cultura italiana detém uma influência muito grande e quando se trata dessas massas mais empobrecidas, uma tendência é julgar que são pessoas de outras etnias, como caboclos ou negros (pejorativamente incluídos na categoria “negrada”) que apresentam baixo rendimento escolar e se encontram em situação de discrepância de idade e série escolar. Esse dado, revelado na pesquisa, demonstra que outros grupos étnicos e sociais compõem a classe de alunos com atraso escolar, que empobrecidos, vivem sob os mesmos preconceitos pela sua condição de fazer parte do grupo “dos diferentes” na escola.

É olhando para essa configuração da classe e seu contexto que precisamos entender como as ações pedagógicas, especificamente para esta classe, foram adotadas (ou projetadas) e que possíveis mudanças foram acontecendo. Retomando Mainardes (2007), a sala de aula é um dos "termômetros" com o qual se mede o grau das mudanças que ocorrem na educação. Nesta perspectiva, entende esse local como espaço rico de mudanças que pode propiciar um lugar de qualidade para todos (MAINARDES, 2007, p. 121). Acrescenta ainda, que não podemos nos conformar com a crença de que as mudanças na escola e no sistema educacional, isoladamente, são suficientes para alterar 
o quadro de crise social ou que possam eliminar as desigualdades e desvantagens determinadas pela condição social (MAINARDES, 2007, p. 192). As mudanças que foram ocorrendo na dinâmica da escola pesquisada foram resultado de um trabalho contínuo e coletivo, como também de avaliações e proposições na perspectiva de superação dos preconceitos em relação à classe.

\section{Classe de Aceleração: caminhos de mudança e suas limitações}

Conforme relatos obtidos na pesquisa, houve resistências à implantação da classe na escola por parte de alguns professores e mesmo da direção, nesse período. Primeiro, porque os professores questionavam a justificativa de criação da Classe A para os problemas somente de distorção de idade e série. Segundo, por atribuir que a instalação de uma turma com tal finalidade, passa a ser uma forma dissimulada de preconceito, até mesmo com a mudança de nome Classe de Aceleração para Classe A. Enfim, pode-se inferir que a sua institucionalização representa uma forma disfarçada de segregação escolar ao reunir, em uma classe, apenas aqueles alunos que não apresentam o perfil escolar formalmente esperado.

À medida que a Classe de Aceleração foi sendo estruturada, a sensação que havia era de que a escola parecia simplesmente "empurrar" para frente o aluno com problemas de um passado escolar, em sua essência excludente, resultado de um processo ou construção histórica. Essa observação faz sentido, pois, quando um aluno se tornava inconveniente para o professor em sua turma regular, não raro transferia-se para a Classe de Aceleração, típica da alusão “manda pra classe”, citada em algumas entrevistas.

A implantação das Classes de Aceleração $^{5}$ passa a ser um dispositivo com o propósito de preencher uma lacuna da educação escolar básica, na tentativa de minimizar a problemática não só das distorções de idade e série, mas também sociais e

\footnotetext{
${ }^{5}$ De acordo com Bolzan (2011), as classes de aceleração compreendem aceleração de estudos para alunos de diferentes idades e séries que não conseguiram vencer as séries na escola pública. As classes de aceleração foram asseguradas pela Lei $n^{\circ}$ 9.934/96, art. 24, inciso V, alínea b, e pela lei Complementar $n^{\circ}$ 170/98, art. 26, inciso VI, alínea d, obedecendo as diretrizes abaixo explicitadas: Nível 1, para alunos que ainda não se apropriaram do conhecimento necessário à aprendizagem da leitura e da escrita; Nível 2, para alunos que não se apropriaram dos conceitos essenciais das diversas áreas do conhecimento nas séries iniciais do ensino fundamental; Nível 3, para alunos que não se apropriaram dos conceitos essenciais das diversas áreas de conhecimento nas séries finais do ensino fundamental (BOLZAN, 2011, p. 14).
} 
pedagógicas. À medida que o trabalho com a classe foi se ampliando, as ações pedagógicas que se desenhavam demonstravam não darem conta da proposta original de correção de fluxo dos chamados diferentes. Entender, a partir da forma como a classe foi introduzida na escola, as estratégias, as impressões, reações e atitudes dos alunos, dos professores e gestores, o que mudou e ainda permanece com relação aos preconceitos com os chamados diferentes, é o que vamos destacar a seguir.

Enumeramos algumas ações que foram se somando e produzindo mudanças no interior da escola e da Classe de Aceleração, sobretudo voltadas para a superação de muitos preconceitos direcionados aos alunos desta classe. Destacamos entre elas: a manutenção de uma professora de tempo integral para a classe; a mudança da denominação de Classe $A$ para $9^{\circ}$ ano e da sala que passou a funcionar no mesmo bloco das turmas regulares; a inserção de novas disciplinas como Artes, Educação Física, Inglês; o trabalho coletivo da professora titular com os demais professores e uma nova gestora com uma concepção diferente da anterior sobre os alunos em atraso escolar; a inserção dos alunos nas atividades/eventos da escola; a composição da turma com no máximo 25 alunos. Essa condição de limite do número de alunos e de uma professora exclusiva para a turma exerceu um efeito importante no funcionamento da classe, como observou uma das professoras entrevistadas: "Esse trabalho funciona, porque os alunos têm uma professora que se dedica a eles vinte horas semanais, matutino na turma, mais vinte horas de atendimento vespertino (reforço) praticamente individual, isso auxilia muito eles".

De acordo com o depoimento de outra professora da classe, o empenho da escola foi muito grande, pois teve que ir mudando juntamente com os alunos para entender que as ações empreendidas tinham que passar também pela mudança da escola como um todo. Essa ideia só começou a ganhar força em 2013 quando a nova gestora assumiu a direção da escola e, junto com a professora da classe, abraçou o propósito de mudar a dinâmica de trabalho e consequentemente, a percepção negativa em relação à Classe de Aceleração. A aproximação mais efetiva com a turma de alunos desta classe possibilitou as primeiras mudanças que foram acontecendo lentamente. Mais precisamente em 2014, com o envolvimento docente no trabalho com a classe, as ações citadas acima foram ganhando força e maior adesão. Nos dois primeiros anos de funcionamento da classe 
havia somente uma professora responsável, com dedicação em tempo integral, razão pela qual a chamaremos de professora titular.

Consideramos também que os profissionais envolvidos com a classe fizeram a diferença, mesmo representando "apenas a ponta do iceberg", como avaliou uma entrevistada. Essa diferença está no que é chamado "efeito professor" (MARAFELLI, 2011, p. 99). Nesse sentido, retomando a autora, concordamos com o efeito professor e, reforçamos ainda, o da gestão da escola, nas mudanças ocorridas. A escola, através da professora titular, com apoio de outros professores e da gestão, adotou práticas pedagógicas, que ao longo do tempo produziram resultados escolares mais favoráveis à integração dos alunos. Esse efeito, por assim dizer, estava muito presente na dinâmica adotada pela professora titular, em sua organização e praticidade em lidar com momentos tensos que foram observados, mesmo quando se realizava o trabalho de pesquisa. Os constantes diálogos, dinâmicas de trabalho, exigências, firmeza e disponibilidade, foram alguns desses elementos significativos de mudança. No conjunto das ações, não podemos desconsiderar o "clima escolar", outro aspecto destacado por Marafelli (2011, p. 65), que representa uma espécie de personalidade coletiva da escola, uma atmosfera geral que pode ser percebida ou sentida no ambiente geral do estabelecimento de ensino.

Conforme já observamos, a Classe de Aceleração inicialmente estava espacialmente isolada das turmas regulares. A mudança de designação da turma para $9^{\circ}$ ano $\mathrm{V}$, conforme reivindicação dos próprios alunos, assim como o deslocamento da classe para o mesmo bloco das turmas regulares, tiveram um significado importante, na medida em que o grupo não ficava espacialmente isolado, uma vez que circulava nos mesmos espaços com os alunos das demais turmas. Essa mudança e sua importância se resumem nas palavras desta professora entrevistada, ao destacar os avanços que o conjunto das atividades com a classe foi possibilitando:

Não havia mais salinha separada; não havia mais a Classe A e sim o nono ano cinco; o vínculo mais estreito entre a direção, professores e a turma; o envolvimento dos alunos nas atividades escolares, desde os jogos inter classe até o show anual de talentos promovido pela escola. 
De acordo com o depoimento de outra professora da classe: "Muita coisa tem mudado, essa é apenas a ponta do iceberg". Os alunos vão percebendo que um dos problemas da não aceitação da condição em que estão inseridos, reside também na própria percepção do mesmo como alguém que se considera rejeitado e que acaba rejeitando o outro. Em tom de satisfação com os resultados, acrescentou: "Foi uma das melhores classes que a escola teve". E o interessante dessa afirmação é que ela não é de uma professora somente, mas passa a ser do aluno, da direção e de todas as pessoas ligadas à classe, do conjunto da obra. Conclui: "Para que os alunos mudem, precisamos primeiro mudar nossa visão".

Em síntese, a pesquisa permitiu constatar que o preconceito dirigido aos alunos da classe se explica, sobretudo, pelo fato de pertencerem a uma determinada turma de estudantes com atraso escolar, sem desconsiderar, evidentemente, os efeitos de outros pertencimentos sociais (econômico, racial, de gênero, entre outros). Quando o aluno é inserido em uma classe estigmatizada, que recebe os "diferentes", os desiguais em histórico escolar e social, os “da turma dos que não aprendem”, “da turma dos reprovados", entre outras rotulações dirigidas à classe e seus alunos, tornam as relações, no interior da escola, mais tensas e reforçam estereótipos que ainda sobrevivem na instituição.

\section{Classe de Aceleração: o que dizem os alunos}

Conforme já adiantamos, quando foram iniciadas as atividades em 2012, a classe era vista na escola com certa reserva e por vezes com certo desprezo, realidade que já foi sentida nos primeiros dias de atividade, conforme depoimento da professora titular. Entre algumas expressões e situações que exemplificam comportamentos de rejeição, advindos de professores contrários à inserção da classe na escola, destacamos: "vocês (os professores) vão trabalhar com a turma do refluxo?". Outra, dirigida à professora titular, quando os alunos da classe confeccionaram ${ }^{6}$ uma camiseta, e outra professora perguntou: "Você não tem vergonha em usar uma camiseta onde está o teu nome, junto

\footnotetext{
${ }^{6}$ É comum as turmas dos $9^{\circ}$ anos confeccionarem uma camiseta com um slogan da formatura e o nome do professor regente e de toda turma. Da mesma forma, a Classe A confeccionou a sua.
} 
com os dos alunos que não aprendem?" Ou, quando a turma da classe passava com a professora pela secretaria da escola e outra professora falou: "Aonde você vai com esses marginais?". Ainda: "Como você pode trabalhar com esse tipo que não aprende nunca?". Citamos algumas expressões e situações, relatadas por professores nas entrevistas, que dispensam comentários, pois não mascaram a agressão dirigida tanto aos alunos da classe como aos professores que trabalham com eles.

Os depoimentos obtidos ao longo da pesquisa nos permitem afirmar que uma das dificuldades mais constrangedoras que enfrentaram os alunos da Classe de Aceleração, já no início do ano letivo, foram os rótulos atribuídos a eles e à classe que frequentavam. Os efeitos dessa situação são multiplicados uma vez que, como observa Bolzan (2011, p. 100), “os rótulos atribuídos aos educandos contribuem, de forma decisiva, para afirmar o fracasso escolar e os processos de exclusão".

Para enfrentar essa realidade, houve um empenho por parte dos professores e gestores para que a nova classe pudesse conquistar reconhecimento. No entanto, os preconceitos em relação à turma que reúne alunos marcados pelo fracasso escolar não foram totalmente eliminados, conforme revelaram os alunos entrevistados. Assim, nesta parte do texto, procuramos dar voz a esses sujeitos que, apesar dos problemas que enfrentaram no dia a dia, foram fazendo sua caminhada, deixando explícito o desejo de continuar estudando.

Embora os alunos descrevam como positivo o fato de pertencerem à classe e, assim, terem oportunidade de acelerar os estudos, não deixam de revelar igualmente os dissabores da condição de fazer parte de uma turma de aceleração. Suas revelações denunciam a permanência de práticas discriminatórias, mesmo diante da mobilização ocorrida na escola que acena na perspectiva de mudanças. Durante as entrevistas, foram muitas as expressões repetidas pelos alunos a respeito do que ouviam sobre eles e a turma. Dada sua importância, contabilizamos aquelas que, pela sua recorrência, ganharam maior destaque nas entrevistas: "turma de burros", citada 32 vezes; de “reprovados", 16 vezes; de "atrasados", 11 vezes; "que não aprendem”, 7 vezes. São expressões que revelam a carga negativa sobre como a classe é compreendida e vista no ambiente escolar. Apesar das hostilidades sofridas, os alunos entrevistados destacaram também aspectos positivos atribuídos à classe, que poderemos chamar de mudanças. São 
eles próprios dizendo que na classe tinham "tratamento igual", citado 32 vezes; consideraram bons "a classe e os estudos", 30 vezes; "chance de aprender mais", 19 vezes; "continuar os estudos", 18 vezes; "recuperar os estudos", 8 vezes; "ajuda bastante”, 8 vezes; “é uma sala normal”, 32 vezes; “fomos acolhidos”, 6 vezes e "é um lugar só da gente". Se formos considerar o total das respostas, podemos verificar que há maior número de expressões positivas do que negativas, parecendo sinalizar que ocorreram mudanças favoráveis no funcionamento e percepção da classe na escola. Apesar dessas sinalizações, elas não minimizam nem escondem os estereótipos e preconceitos que, como revelou à pesquisa, ainda permanecem na escola e, consequentemente, na forma como os alunos se veem e são vistos.

As histórias não documentadas (EZPELETA; ROCKWELL, 1986) da escola estão repletas de violências simbólicas tais como de expressões, em forma de piadas, entre outras, dirigidas aos alunos considerados "os diferentes da escola", aqueles que "não aprendem", ou outras já citadas. Um de nós pode constatar os efeitos dessa violência voltada aos jovens, em um dos primeiros contatos com a Classe A em 2013. Na ocasião, acompanhava o Programa Escola da Família, desenvolvido pela Secretaria Municipal de Educação e, perguntando aos alunos “o que é a classe”, a resposta foi imediata: “Essa é a turma dos burros", “dos retardados" "dos que não aprendem". Pareciam dizer "honestamente", pois assim se consideravam como estudantes com distorção de idade e série, cujo desempenho, comportamentos e perfis sentiam como muito "diferentes" do esperado. Os comentários "sentidos", como os que acabamos de citar, estavam sempre presentes na ordem do dia escolar e tal era a sua naturalização, que pareciam não mais causar espanto ou comoção, porque já haviam sido incorporados no cotidiano da escola.

Ao considerar como os alunos eram vistos na escola e na classe, necessariamente prestamos atenção em outro ponto, ou seja, como eles próprios se veem, e esse "se ver", diante de si e dos demais colegas da sala ou mesmo da escola reflete, em sua essência, na capacidade de interação social, seja na escola ou fora dela. Quando uma aluna da classe diz que "às vezes é bom não pensar muito para não se sentir excluída", ela só está reforçando uma máxima de Bourdieu sobre as formas dissimuladas de segregação. Ou seja, não é bom olharmos muito, talvez, só fazermos de conta às vezes. É preciso, portanto, rever criticamente quando os alunos dizem "não haver preconceito", "trata 
todo mundo igual”, "me sinto normal", pois o lado oposto dessas afirmações está presente de modo explícito ou mais velado, no dia a dia da escola, em suas múltiplas formas. Os depoimentos abaixo, retirados das entrevistas dos alunos, revelam parte da realidade que vivenciaram como integrantes da classe:

O relacionamento dos alunos da classe é bom. No recreio sim, eles fala que é tudo reprovado. Eu fico quieto. Chamam nós de burro porque nós tá lá dentro. Só alguns fala. Fica só a nossa turma no canto. Só um grupinho, uns sete, oito... (Aluno 8)

Tem professor que diz que nós não vai ser nada na vida, tem que expulsar da escola. Que não tem mais jeito. Esses professores não procuram entender o aluno. (Aluno 6)

Já tentei desistir, a mãe não deixou. Me sinto bem e quando começo a pensar demais parece que somos excluídos, mesmo em casa parece que somos excluídos. Mas é nós que estamos nos excluindo. A gente pensa só nas coisas ruim que os outros fizeram. Pensa nas coisas que os outros fizeram com a gente, e aí a gente se exclui. (Aluno 4)

As formas pejorativas de rotular os alunos da classe ("aluno burro", o "que não aprende", o "reprovado", etc.), como uma espécie de círculo vicioso, causam certa angústia também no pesquisador, principalmente quando vindas de professores e dos conselhos de classe, pois representam formas de classificação e estratificação, desde a questão social, de aprendizagem, entre outras tantas formas. Bourdieu e Champagne (BOURDIEU, 2012) contribuem nessa análise sociológica da condição dos estudantes à margem do sistema de ensino, numa situação de "excluídos do interior", como também reforça Freitas (2007), ao argumentar que

[...] há hoje um grande contingente de alunos procedentes das camadas populares que vivem o seu ocaso no interior das escolas, desacreditados nas salas de aulas ou relegados a programas de recuperação, aceleração, progressão continuada e/ou automática, educação de jovens e adultos, pseudo-escolas de tempo integral, cuja eliminação da escola foi suspensa ou adiada e aguardam sua eliminação definitiva na passagem entre ciclos ou conjunto de séries, quando então saem das estatísticas de reprovação, ou em algum momento de sua vida escolar onde a estatística seja mais confortável. (FREITAS, 2007, p. 968) 
Essa condição de "excluídos do interior", de acordo com os dados e as circunstâncias apresentadas, demonstra que, por mais eficaz que possa ser o trabalho pedagógico e as boas intenções com os alunos em atraso escolar, estes podem, dissimuladamente, reforçar as desigualdades educacionais. Exemplificamos essa observação com a separação que ocorre nas práticas de composição das turmas regulares, quando o aluno com mais dificuldades escolares é “empurrado" para o fim da fila para, possivelmente, compor a Classe de Aceleração, como uma espécie de dispositivo claro dessa separação de classe escolar.

Destacamos um conjunto de situações, em que alunos e professores aparecem diante da necessidade pulsante a nos provocar a pensar, de que nossas realidades escolares e suas dinâmicas de inclusão necessitam de mudanças mais sistêmicas com uma compreensão mais global de educação, considerando as experiências locais como primícias na promoção da mudança dessa lógica de reprodução.

\section{Considerações finais}

O histórico de implantação da Classe de Aceleração e suas repercussões no cotidiano da escola e na vida dos alunos revelam a dinâmica complexa das relações no interior da escola e da política de superação do atraso escolar nas condições postas. Não existem vencedores e perdedores dados a priori nessa dinâmica dos preconceitos, e sim movimentos dialéticos que devem ser observados e estudados com mais cuidado, a partir das possibilidades que se apresentam juntamente com os fatos e com as relações estabelecidas e as construções conceituais de trabalho para cada época e, consequentemente, para cada grupo ou turma. Os distanciamentos que ocorrem entre o que de fato acontece e o que se estabelece como meta de trabalho para evitar tensões, exemplificam as dificuldades que cada um sente em mover-se nesse mundo de conexões divergentes. Coexistir nesse meio já é uma forma de luta muito grande em querer mudar, mas com a lucidez de quem sabe o quanto as mudanças reais se arrastam.

Olhando para a turma da Classe $A$, na escola pesquisada, temos a impressão de que tudo se move em uma espiral sempre eterna, na qual esses alunos são deixados ou rearranjados numa segunda esfera ou estrato em que, direta ou indiretamente, ainda 
sofrem os estigmas da segregação, de um apartheid dissimulado sobre a tentativa heroica de alguns educadores em lutar para ao menos minimizar alguns sofreres cotidianos. Logo, trabalhar na tentativa de ressignificar esse substrato da história que pouco ou quase não interessa às exigências "polidas e empreendedoras" da sociedade moderna é o que torna nossa vida e nosso trabalho mais bonito e humano.

Enfim, as mudanças que foram acontecendo ao longo da trajetória da classe na escola estudada, representam uma mudança positiva, embora não suficiente, nas relações com o outro, com o diferente, embora o que permanece diluído ou disfarçado em preconceitos e rotulações parece não destacar o que de bom é feito na educação. É $a$ velha dificuldade em não sabermos ao menos equalizar as coisas boas que acontecem com o que de preconceitos permanecem. Pois, se as relações sociais macro estão comprometidas por uma lógica de dominação e opressão, na qual a escola dissimuladamente vai reproduzindo um modelo dominante e excludente, por outro lado, não se pode ofuscar os avanços que, mesmo em pequena escala, vão acontecendo no cotidiano das escolas. A impressão que temos é de que acabar com algumas estruturas sociais precárias vai sintomaticamente acabar com uma outra estrutura que sobrevive dessa precariedade. A educação é uma obra a muitas mãos e a escola não é uma entidade isolada da sociedade, por isso mesmo, não pode assumir todo o ônus pela redução das desvantagens educacionais, em grande parte determinadas pelas condições políticas, sociais econômicas e culturais. 


\section{Referências}

BALL, Stephen J.; MAGUIRE, Meg; BRAUN, Annette. Como as escolas fazem as políticas: atuação em escolas secundárias. Ponta Grossa: Editora UEPG, 2016.

BOLZAN, Ourora Rosalina. Cultura e escola: processos de inclusão/exclusão de caboclos. Chapecó: Argos, 2011.

BOURDIEU, Pierre; CHAMPAGNE, Patrick. Os excluídos do interior. In: BOURDIEU, Pierre (coord.). A miséria do mundo. 9. ed. Petrópolis: Vozes, 2012.

BOURDIEU, Pierre; PASSERON, Jean Claude. A reprodução: elementos para uma teoria de ensino. 3.ed. Rio de Janeiro: Francisco Alves, 1992.

CANDAU, Vera Maria Ferrão. Diferenças culturais, cotidiano escolar e práticas pedagógicas. Currículo sem Fronteiras, Rio de Janeiro, v. 11, n. 2, p. 240-255, jul./dez. 2011.

CARVALHO. Marília Pinto de. O fracasso escolar de meninos e meninas: articulações entre gênero e cor/raça. Cadernos Pagu v. 22, p. 247-290, 2004.

COIMBRA, Sandra Regina da Silva. Reprovação e interrupção escolar: contribuições para o debate a partir da analise do projeto Classes de Aceleração. 2008. 228 f. Tese (Doutorado em Educação) - Universidade Federal de Santa Catarina, Florianópolis, 2008.

EZPELETA, Justa; ROCKWELL, Elsie. Pesquisa participante. São Paulo: Cortez; Autores associados, 1986.

FREITAS, Luiz Carlos. Eliminação adiada: o ocaso das classes populares no interior da escola e a ocultação da (má) qualidade do ensino. Educação \& Sociedade, Campinas, v. 28, n. 100, p. 965-987, out., 2007.

MAINARDES, Jefferson. Reinterpretando os ciclos de aprendizagem. São Paulo: Cortez, 2007.

MARAFELLI, Cecilia Maria. Efeito professor?: um estudo sobre perfis docentes nos setores público e privado. 2011. 137 f. Dissertação (Mestrado em Educação) - Pontifícia Universidade Católica do Rio de Janeiro, Rio de Janeiro, 2011.

PAIM, Elison Antonio. Proposta curricular de Santa Catarina: ensino de história, memória e patrimônio cultural. OPSIS, Catalão, v. 15, n. 1, p. 235-256, 2015.

PEREGRINO, Mônica. Trajetórias desiguais: um estudo sobre o processo de escolarização pública de jovens pobres. Rio de Janeiro: Garamond, 2010.

POLI, Solange Maria Alves. Aceleração da aprendizagem: de quem? Chapecó: Argos, 2003. 
SANTA CATARINA. Secretaria de Estado da Educação e do Desporto. Coordenadoria Geral de Ensino. Diretoria de Ensino Fundamental. Classe de Aceleração $-\mathbf{1}^{\mathrm{a}}$ a $4^{\mathrm{a}}$ série do Ensino Fundamental. Florianópolis: SEED, 1999.

SÃO LOURENÇO DO OESTE (SC). Decreto n. 1.779, de 19 de dezembro de 2008. Dispõe sobre a Reformulação do Sistema Municipal de Ensino e dá outras providências. São Lourenço do Oeste (SC). [2008]. Disponível em:

http://www.saolourenco.sc.gov.br/arq/legislacao/20140917_105031000000.pdf. Acesso em 01/02/2019. 